\title{
LA ESTRUCTURA DE LAS REDUCCIONES DE MAYNAS
}

\section{Wilfredo Ardito Vega}

Bajo el influjo de las ideas ordenadoras de la baja Edad Media y el Renacimiento, se comenzó a congregar en poblados a los grupos nativos. En este estudio se verá cómo los misioneros de Maynas iniciaron esta tarea y las reacciones y conflictos que esto desencadenó en losindígenas. Esta regulación dela vida cotidiana generó un desequilibrio entre los nativos. En la parte final del artículo, se ve la necesidad de plantear "un diálogo intercultural" con las poblaciones amazónicas para convencer a los nativos de la conveniencia de la vida en las reducciones, más que coaccionar su presencia en ellas.

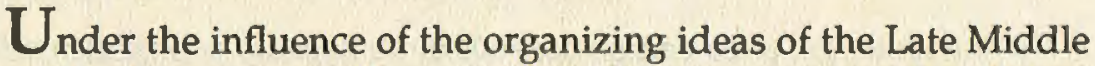
Ages and the Renaissance, the native peoples were gathered together in reductions. In this study it will be seen how the missionaries of Maynas began this task and the reactions and conflicts that this let loose among the natives. The regulation of ordinary life generated a desequilibrium among the people. The last part of the article deals with the necessity of entering into 'intercultural dialogue' with the Amazonian peoples to persuade them to live together the life of the reductions, rather that force them to accept. 


\section{LA GOBERNACION DE MAYNAS}

Consolidada la conquista de los Incas, muchos españoles insatisfechos por el reparto del botín procuraron descubrir nuevos territorios. Varias expediciones se dirigieron a la Amazonía impulsadas por las noticias sobre legendarios tesoros. Sin embargo, las principales riquezas que encontraron fueron los propios habitantes, quienes eran capturados para ser encomendados por los habitantes de ciudades fronterizas como Moyobamba, Lamas y Jaén.'

Los asentamientos al Oriente de la Audiencia de Quito fueron muy tempranos, tanto por la ausencia de yacimientos mineros importantes como por la proximidad a la Amazonía de las principales ciudades españolas. Sin embargo, las sublevaciones de los indígenas sometidos a la encomienda lograban detener muchos proyectos colonizadores.

En 1616, Diego Vaca de Vega, Gobernador de Loja; celebró con el Virrey Príncipe de Esquilache unas Capitulaciones, por las que se le concedía a él y a sus descendientes el título de Gobernadores de Maynas, región que tomaba su nombre de los indios que vivian al sur del río Santiago, en el actual departamento peruano de Amazonas, pero que se extendía hasta donde pudieran llegar sus conquistas.

Ese mismo año partió una expedición que fundó como capital de la Gobernación el poblado de Borja $\left(^{*}\right)$ y repartió a los indios entre los soldados y oficiales. El trabajo en lavaderos de oro y otras faenas originó una violenta sublevación indígena, reprimida cruentamente por el segundo Gobernador, Pedro Vaca de la Cadena. Poco después, el funcionario solicitó al Provincial de la Compañía de Jesús en Quito, el envío de misioneros, pensando que su predicación apaciguaría a los nativos.

Sin embargo, poco tiempo después de su llegada, se produjeron fuertes conflictos entre misioneros y encomenderos pues éstos no permitían a los indios acudir a la doctrina y los sometían a diversos maltratos. Los Jesuitas obtuvieron el respaldo del Gobernador para constituir reducciones donde los indios no fuesen encomendados, y los españoles no pudieran ingresar sin su permiso.

(*) En homenaje a San' Francisco de Borja, abuelo del Virrey. 
Hacia fines del siglo XVII, los funcionarios y soldados españoles, desalentados por la ausencia de oro, el aislamiento de la Gobernación y los impedimentos para el único aliciente que quedaba ${ }_{z}$ el servicio personal de los indios, optaron por retirarse, dejando la administración política de la región en manos de la Compañía de Jesús.

Esta situación de facto fue confirmada por la Corona mediante la Real Cedula del 15 de Junio de 1683, disponiendo que los soldados y oficiales que enviase la Audiencia estarían solamente a las ordenes del Superior de las Misiones (Maroni, p. 202). Esporádicamente, la Corona nombró Gobernadores para Maynas, pero la mayoría de ellos permanecieron en Quito o en Loja.

A diferencia de las experiencias del Paraguay y otras regiones americanas, las reducciones jesuitas de Maynas se caracterizaron por una continua inestabilidad. Los cronistas la explican por las epidemiás y las invasiones de bandeirantes. Sin embargo, la realidad es que tambiẻn los misioneros enfrentaron un fuerte conflicto con los indios. Son frecuentes los relatos sobre fugas y sublevaciones y una decena de jesuitas fueron asesinados en diferentes circunstancias, teniendo como denominador común de estos hechøs la rebelión contra el rígido ordenamiento de la reducción.

Paradójicamente, los misioneros comprendieron la necesidad de contar con respaldo militar para conservar 'a los indios en las reducciones. Cuando las reducciones no pudieron contar con soldados españoles tuvieron el apoyo de auxiliares laicos (viracochas) o formaron tropas indígenas.

Finalmente, la difícil experiencia de Maynas concluyó abruptamente con la expulsión de los Jesuitas de todos los territorios españoles en 1767.

\section{LAS REDUCCIONES COLONIALES}

Una diferencia fundamental entre los patrones de asentamiento indígena y europeo era que desde la Baja Edad Media la residencia en poblados había sido una señal inequívoca de policía, esto es de vida humana, recuperándose el valor de las ciudades como unidad básica de la sociedad(1).

Se consideraba, siguiendo a Aristóteles, que el hombre no debía vivir aislado, pues solamente en una sociedad las capacidades y aptitudes de cada uno podían ser aprovechadas por el resto, siendo el bien común un valor superior al interés individual. 
De esta forma, una de las primeras prescripciones de la Corona fue que los conquistadores se establecieran en poblados, evitando la migración desordenada y la dispersión, para consolidar el dominio sobre una región. Las ciudades servían también de bases de aprovisionamiento, centro comercial y cabeceras de puente para nuevas colonizaciones.

Respecto a los indios, desde que recibió los primeros informes sobre su vida nómada en las selvas, la Corona dispuso que se les congregara en poblados (Instrucciones de Isabel I al Gobernador Ovando, 1503), en lo cual podemos hallar uno de los primeros actos masivos de compulsión hacia los indios.

Se reparten en pueblos que vivan conjuntamente, y que no estén ni anden apartados de los otros por los montes. (Mörner, 1970, p. 24).

No șe ocultaba que se facilitaba así el ejercicio de un poder central, estableciendo reservas de tributarios y fuerza laboral. La obligación de reducir a los indios quedaría finalmente incorporada a la Recopilación de Leyes de Indias como una norma general para todos los dominios de ultramar (L. VI, t. III, ley I), recogiendo una Real Cédula de 1573.

Dado que la concepción urbanista se conjugaba con el pensamiento cristiano, así como que permitía paliar la escasez de misioneros, la Iglesia compartió este interés, como se aprecia en las Instrucciones del Cardenal Cisneros a los Padres Jerónimos (Hanke, p.), inspiradas en buena medida por de Las Casas (Memorial de 1516, citado por Lassegue).

La Recopilación prescribe a Arzobispos, Obispos, sacerdotes diocesanos y religiosos la obligación de colaborar en el proceso de reducciones (L. VI, t. III, ley II).

Estos eran también los planteamientos de los prelados americanos: en 1546 el Concilio de Nueva España decretó la reducción de los indios para que "fuesen verdaderamente cristianos y políticos como hombres razonables que son".

También los Concilios de Lima y los Sínodos del Obispado de Quito promovieron la reducción de los indios en sus respectivas, jurisdicciones.

Que la muchedumbre de los indios que esté esparcida por diversos ranchos se reduzgan a pueblos copiosos y concertados como lo tiene mandado la Magestad Católica (III Concilio Limense, part. 2 n. 80). 
Aunque una Real Cédula de 1549 a la Audiencia de Lima respaldaba la labor de reducción, existieron muchas vacilaciones en cumplir esta orden para no "escandalizar y alterar", según se decía, a los naturales (Toledo, XVII, p. 16). Esta reticencia obedeciô más bien a que la dispersión permitía mantener la autoridad de los encomenderos y debilitaba la centralización de poder que exigia la Corona.

En cambio, los juristas más interesados en reforzar la autoridad real en un proyecto humanista para las Indias, sí mostraban su preocupación porque se llevara a cabo:

nadie ignora los inconvenientes que siguen a los indios de estar apartados $y$ escondidos en huaycos y quebradas, asi para lo tocante a su policia como a su conversión, porque ni pueden ser doctrinados ni ser hombres perpetuamente, no estando juntos en pueblos (Matienzo, p. 48).

En 1572 el Virrey Toledo decidió intervenir sosteniendo que:

no era posible doctrinar a estos indios, ni hacerlos vivir en policia sin sacarlos de sus escondrijos; para que esto se facilitase, como se hizo, se pasaron y sacaron las reducciones a poblaciones y lugares públicos (XVIII, $p$. 17).

Los Jesuitas también consideraban fundamental la concentración de los indígenas de sus misiones en poblados, con la finalidad de atender a su formación humana y cristiana. En las afueras de Lima, en el barrio indígena de Santiago, desarrollaban sus primeras experiencias de este tipo.

Sin embargo, en un primer momento, los Jesuitas rehusaron colaborar con Toledo, afirmando que la experiencia de las doctrinas había causado muchos casos de corrupción entre los religiosos, asi como tenían graves problemas con la presencia de españoles (Ácosta).

Finalmente, aceptaron dirigirse a las zonas fronterizas del Virreynato, en las que podía establecerse un régimen seriamente planificado sin la presencia de encomenderos. Los funcionarios coloniales acogieron estas misiones por cuanto de esta forma se afirmaba la presencia de la Corona en dichas zonas. Aunque los Jesuitas se opusieran a las encomiendas, la concentración de los indios en las reducciones parecía poder permitir el futuro proceso de colonización. 


\section{EL PATRON DE ASENTAMIENTO JESUITA}

Para los misioneros de Maynas, era considerado fundamental, con anterioridad a cualquier esfuerzo catequético, iniciar su trabajo con la reunión de los indígenas en poblados, donde pudieran ser transformados en seres humanos con sus potencialidades aprovechadas y después en cristianos.

(...) lo que se ha de persuadir un misionero que trata de reducir infieles es que su principal trabajo no consiste en otra cosa que en sacar a esta gente brutal de sus bosques y reducirla a vida racional y sociable (Maroni, p. 232).

Dadas las condiciones particulares de la Goberación, fue una característica del patrón de asentamiento la autonomía de los misioneros respecto a las autoridades coloniales. Estaban legalmente prohibidos los establecimientos o traslados de reducción no autorizados por el Presidente de la Audiencia (RLI, L. Vi, t. III, ley 13), probablemente debido a decisiones arbitrarias de los doctrineros.

Sin embargo, aunque los Jesuitas tenían un procurador ante la Audiencia de Quito, no solicitaban autorizaciones previas para las fundaciones o traslados de poblados, al parecer por razones de distancia, sino que se limitaban a pedir la confirmación de los fundados (p. e. ANH 20 de Julio de 1702, f. 4).

La planificación centralizada y el continup flujo de información existentes en las misiones llevaba a que toda decisión al respecto tuviera el previo conocimiento del Superior o del Visitador, aunque no siempre los informes que recibian eran totalmente objetivos.

Sin embargo, los diversos caracteres del nuevo patrón de asentamiento ocasionaron muchos conflictos con la población indígena.

\section{El Sedentarismo}

El establecimiento permanente en una localidad era particularmente contrario a los hábitos tradicionales indígenas. A pesar de la exhuberante vegetación el suelo de la Amazonía posee una mínima cantidad de nutrientes, lo que imposibilita un cultivo sostenido y en gran escala. Además, aunque 
la fauna es muy variada en cuanto a especies, la densidad poblacional de cada una de éstas es muy reducida.

Estas restricciones llevaron a la población originaria a un patrón de asentamiento disperso en pequeños grupos de familias extensas. Solamente en las orillas del Amazonas y los ríos principales, se pudieron establecer poblaciones más estables con anterioridad a la llegada de los europeos (Maroni, p. 175; Acuña, Meggers).

Las actividades económicas principales eran la caza, la pesca y la agricultura de roce y quema. Estas formas de subsistencia acarreaban luego el traslado del grupo a otra región, conforme disminuían los recursos animales y se producía el agotamiento del suelo.

Otras veces, el traslado se debía a fenómenos naturales, como las inundaciones periódicas o sequías, aunque también era factible que escasearan los recursos por una circunstancia climática especial. Finalmente, muchas migraciones eran causadas por guerras o por creencias sobrenaturales: el grupo abandonaba el lugar donde había fallecido uno de sus miembros por temor a sufrir una desgracia (p.e. Uriarte, p. 338).

Los misioneros no desconocían ni las limitaciones del suelo amazónico ni los mecanismos nativos de adaptación, como lo comprueba uno de los primeros informes que tenemos:

Las mismas tierras en sus sembrados, si dan copiosamente sus frutos, .a las segundas siembras amaynan, y los frutos que se cogen en las cosechas a pocos meses se corrompen o acaban. Por esta causa san mudar las sementeras en nuevas tierras, tomando el travajo de limpiar [191/2] y desmontar la espesura de montaña braba y su grande arboleda, dejando las que una vez sembraron, por muchos años, porque quedan cansadas y sin bigor hasta qué crie nuebo monte (Figueroa, pp. 191-2).

Sin embargo, provenían de una cultura donde el trasladarse continuamente era privativo de grupos marginales, de mala conducta o dudosa moralidad.

Esta concepción reforzaba en los Jesuitas el cumplimiento de su obligación legal de mantener a los indios en las reducciones. La permanencia 
era importante para garantizar la constancia en el proceso de formación impartido mediante la doctrina y la misa dominical.

Los misioneros elaboraban un catálogo o nómina con todos los padres de familia que habían levantado su casa y preparado su chacra. Ellos no debían salir del terreno de la reducción para evitar que contactasen con otros grupos que pudieran incitarlos a huir, recordándoles su antigua libertad.

Los primeros Jesuitas fueron muy restrictivos en cuanto a permitir las salidas de las reducciones, impidiendo a los indios también salir a extraer tortugas y pescado en los periodos en que eran más aprovechables (Figueroa, p. 165). Parece ser que los misioneros llegaban a controlar también el uso de canoas (Uriarte, p.)

Paulatinamente alcanzaron mayor comprensión sobre las necesidades que los nativos y ellos mismos tenían de estos productos y establecieron un sistema rotativo de licencias para salir de la reducción (Uriarte, pp. 217 y 235).

Quedaba al criterio de cada misionero autorizar las salidas, permitiendo algunos que duraran hasta varios días, siempre que estuvieran el domingo de regreso (Uriarte, p. 137).

En la noche se aplicaba el toque de queda destinado a impedir las ceremonias rituales tradicionales, debiéndose en todo caso pedirse permiso para salir (lbid., p. 111).

\section{Los Traslados Forzosos}

La elección del lugar donde se asentaría la reducción correspondía siempre a los misioneros (Maroni, p. 199; Uriarte, p. 110), quienes debían procurar las condiciones adecuadas para la vida humana.

Se consideraba la topografía, las fuentes de agua, tierras comunales y. comunicación (Armani, p. 87). Los misioneros cuidaban que se tratase de una zona elevada, para evitar las inundaciones, pero cuidando que fuera accesible el agua (Maroni, p. 105).

Sin embargo, los asentamientos indigenas parecieron a los Jesuitas pocas veces adecuados. Se combinaba un argumento ideológico: (vivir en la 100 
selva era un rasgo de animalidad) con finalidades prácticas:

Hay que sacarlos de tierras intratables para todo (Figueroa, p. 251).

Uno de los grandes estorvos que hay. para que los Indios no reciban bien la Doctrina Christiana, ni puedan olvidar la natural fiereza que tienen, entrando en la vida política de los hombres, es el vivir de ordinario en los montes y quebradas de los ríos (Peña, loc. cit.).

Dichos lugares eran malsanos y de difícil acceso para los jesuitas, quienes requerían de una constante comunicación, por las exigencias de centralización de información y decisiones propias de la Compañia:

Entabaladas mejor las missiones con disposicion de que los Padres estén acompañados o cercanos unos de otros, y teniendo buena comunicación con los Superiores, colegios y otras partes de fuera (...) todo sera mas llevadero (Figueroa, p. 277).

como por las necesidades de materiales y vituallas que llegaban desde Quito, a través de los llamados despachos.

Prácticamente todos los grupos nativos fueron obligados a migrar y a establecerse donde decidieran los misioneros (2).

Los que habitaban en tierra firme (zonas interfluviales) eran trasladados a la orilla de los ríos principales (Maroni, p. 206), mientras que los grupos ribereños eran concentrados en los lugares que los misioneros evaluaban y que ofrecieran los resultados que buscaban (Golob, p. 218).

Generalmente, al referirse a una comarca los informes mencionaban a los grupos que la habitaban antes de ser reducidos:

entra en Pastasa un riacho llamado Guasaga, cerca del cual vivian cuando gentiles los Andoas guasagas (Maroni, p. 97).

y cuando describian una reducción señalaban el lugar de donde provenian los nativos:

[en Lagunas] viven los Panos, Cocamas y otras naciones traidas en gran parte de las riberas de Ucayale, menos los Cocamillas, que vivieron tres o cuatro dias más arriba en la ribera del río (Id., p. 107). 
Aunque parece que los Jesuitas se preocupaban de que el lugar donde establecían una reducción fuese del agrado de los indios:

Procurase hagan la mudanza en los parajes cercanos a su natural (Figueroa, p. 251),

y evitar que se disgustaran mucho (Zárate, p. 443), a veces desconocían las implicancias negativas de alguna zona, así como su proclividad a las inundaciones o los problemas para abastecerse de recursos valiosos. Las Leyes de Indias prohibían el traslado de los nativos a regiones distintas de su hábitat (R. C. 28.10.1541, citada por Hampe), por los peligros que ocasionaban para su salud, pero esto no parece haber sido un condicionamiento importante en las decisiones de los Jesuitas.

Por ejemplo, las poblaciones que habitaban en la tierra firme poseian hábitos alimenticios basados en la caza; muy distintos de aquellas ribereñas, basados sobre todo en la pesca y en la captura de tortugas. Los misioneros consideraban que llevándolos a las riberas podrían comerciar con otros pueblos y aprender nuevos oficios (Maroni, p. 208), pero la sola visita a esas zonas causaba rechazo en los nativos (Golob, pp. 214-5).

Además, los ribereños también se oponían a que lós Jesuitas, procurando evitar las inundaciones y construir mejores casas, los trasladaran a zonas altas:

Muchos [Omaguas] recelan vivir en tierra firme, por estar entrambas bandas como aradas de diversos caminos por donde bajan al rio los gentiles que viven en el interior del bosque, deseosos de matar Omaguas, por los muchos que estos han muerto y cautivado de asechanza, como señores y corsarios (Maroni, p. 335).

Muchas veces existía además el temor de que los Jesuitas quisieran trasladarlos para entregarlos a los encomenderos. Sabemos que los indios Andoas y Cahuapanas fueron llevados a trabajar en las frías haciendas de Riobamba (Ibíd., pp. 99-100). A mediados del siglo XVIII se informa que muchas mujeres y jóvenes eran conducidos a Archidona, por un hermano que después sería expulsado de la Compañía (Uriarte; Jouanen, t. II, p. 476). Estos hechos eran difundidos y exagerados en los mecanismos indígenas de comunicación. 
A veces una epidemia o un ataque originaban el traslado de un poblado, pero siempre éste requería de la decisión final del misionero (Maroni, p. 364), quien interpretaba los intereses de los indigenas, considerando también la conveniencia para la misión. Por ejemplo, muchas reducciones eran establecidas como puestos intermedios para posteriores expediciones hacia otros grupos nativos (lbíd., p. 113).

En ocasiones las motivaciones de los misioneros llegaban a ser puramente personales. El Padre Uriarte critica, como una práctica habitual, que los misioneros pretendieran, por una cuestión de prestigio, que las reducciones que habian fundado prosperaran o subsistieran a las fugas y epidemias, obligando a residir en ellas a los habitantes de los poblados nativos o de otras reducciones (Ibíd., p. 446).

De todas formas, los traslados forzosos persistieron durante toda la experiencia jesuita. Solamente Uriarte planteó en varias oportunidades tener cautela para evitar las enfermedades o el disgusto de los indios (Uriarte, p. 358).

Señaló inclusive la necesidad de que los misioneros se sacrificaran conviviendo con los nativos en sus antiguos poblados, hasta que ellos comprendieran las ventajas de establecerse donde se les recomendaba.

Criticando la mencionada preferencia por las reducciones ya fundadas respecto a los lugares donde vivían los indios, afirma:

Mas si se miran las cosas con perfecta claridad no nos apegaremos más en uno que otro, y miraremos los inconvenientes grandes de apartar a los indios de sus puestos donde se han criado; yo no hallo más remedio para adelantar aquellas misiones sino sacrificarse los misioneros y vivir en temples y puestos sangrientos hasta que, ya pasados muchos años [448/9], poco a poco se vayan sacando, no todos a un tiempo, sino algunos muchachos y huérfanos a los pueblos del Marañón ya fundados (Ibid., pp. 448-9).

Esta posición no parece producto de una reflexión colectiva, sino de las propias experiencias personales de Uriarte. Nótese, sin embargo, que Uriarte plantea más bien un problema de método y de etapas. El tampoco duda que los asentamientos dispuestos por los jesuitas fuesen los más convenientes para los nativos, sino cree que se deben adecuar a ellos paulatinamente. 


\section{Los Poblados Grandes y la convivencia de Grupos Etnicos}

Otro elemento dentro del patrón de asentamiento jesuitico fue que los misioneros procuraban formar poblados grandes, señalándolo en sus informes como un logro importante.

Tanto el Tercer Concilio Limense como los Sínodos del Obispado de Quito establecían que cada sacerdote debía atender a un número mínimo de fieles aun en las zonas de misión.

Se tiene información sobre la existencia de grandes cacicazgos en las orillas del Amazonas, que impresionaron a los primeros españoles que los recorrieron. Diversos estudios insisten en que la várzea sí es capaz de sostener a un número mayor de habitantes del que se suponía.

Sin embargo, fuese por las epidemias o por las expediciones portuguesas, a la llegada de los Jesuitas estos cacicazgos habían desaparecido. Los nativos, con los que los Jesuitas trabajaban no tenían la experiencia de residir en poblados mayores. Un informe del Padre Julián lamenta que no puedan vivir juntas más de cien personas (Matthei, p. 404), porque se producían conflictos, lo cual nos parece que debió ser muy generalizado, de acuerdo a lo que indican también estudios recientes sobre la conformación de las Comunidades Nativas (Brandt).

(...) reynando entre varios tal tenacidad en no querer unirse juntos en un pueblo, aunq. sean parientes, o poco distaren, por la antipatía natural, q. entre sí se tienen (Magnin, p. 473).

Estos problemas se manifestaban también cuando llegaban otros nativos a reducirse, así fueran del mismo grupo (Uriarte, p. 110).

Por otra parte, a menudo, los Jesuitas sólo conseguian conducir a las reducciones a un número muy pequeño de integrantes de cada grupo étnico (denominados naciones por los Jesuitas). Ni la escasez de misioneros ni los criterios mencionados, permitian asentar a cada grupo en forma particular. Se vieron por ello en la necesidad de reunir en la misma reducción a pequeños grupos de distintas naciones (Figueroa, p. 199) (3).

Sin embargo, esa convivencia era rechazada con mucha frecuencia, pues existian una serie de conflictos tradicionales. Dentro de la concepción predo- 
minante se consideraba solamente como seres humanos a los miembros del propio grupo étnico, lo que se evidencia desde su autodenominación. No habían obligaciones morales con los extraños y esto permitía a los indígenas el desarrollo de la actividad guerrera y la muerte de enemigos como señal de virilidad

Los Jesuitas percibían que el conflicto permanente reforzaba el patrón de asentamiento disperso (Matthei, p. 252) y que plantear una convivencia repentina era muy difícil:

ay casos en q. si la Nación no pasare de uno, éste hará su fuego aparte, como si fueran muchos, no sólo en su casa, sino también en los caminos; comiendo separadamente, mientras los demás comieren juntos (Magnin, loc. cit).

Refiere Rodrigo Barnuevo que entre Avijiras y Encabellados era tal la hostilidad que aún trasladados a Quito debían estar separados para evitar que se agrediesen físicamente (Barnuevo, p. 121; v. también Maroni, p. 215).

Dadas las experiencias anteriores, era natural el temor a una amenaza real o sobrenatural:

A la pereza se añade el odio y enemistades con que por lo común viven entre si reñidas y sospechas de que otros que no son sus inmediatos parientes los hechicen (Maroni, p. 204).

Hay que señalar que realmente los habitantes de una reducción seguían viendo a otros grupos nativos aún no reducidos como sus enemigos y pretendían realizar con el misionero expediciones en su búsqueda, con la finalidad oculta de atacarlos y matarlos (4).

Se menciona por tanto la dificultad en señalar incluso la ubicación del pueblo, pues cada grupo pretendía que fuera en su territorio:

de aqui es que el uno aborrece la vecindad del otro, y en procurando el padre juntarlos en un pueblo muchos se resisten, alegando sus temores y riñas antiguas: este quisiera se hiciese el pueblo en un sitio, otros en otro más accomodado (sic) a su capricho; cada uno quisiera mandar, nadie quisiera obedecer, principalmente a sus émulos y contrarios (Maroni, loc. cit., $v$. también p. 237, Zárate, p. 416 y Magnin, p. 495). 
El conflicto podía mantenerse latente:

Vivian yameos y nahuapaes, estos trasladados de otro pueblo con mucha repugnancia por el sitio bueno que dejaron y antipatía con los de San Regis (Uriarte, p. 216, v. también p. 286).

Pero podía desencadenarse, originando desde una fuga definitiva

Quiso juntar con el Partido de Masamaes el anejo de Mayorunas, por lo que se le unieron los más (Ibíd., p. 368, v. también 205),

hasta asesinatos repentinos (Ibíd., p. 129 y 326). Todo ello obligaba a los misioneros a separar a los que no podían vivir en armonía.

Tenemos el caso de la reducción de San Ignacio de Pebas, donde residían los Pebas y Caumares. Alrededor de 1737 se propuso a los Ticunas trasladarse a ese poblado, puesto que se llevaban bien con los Pebas. Sin embargo, poco después éstos sufrieron una epidemia de catarro, que ocasionó algunas muertes.

Dentro de la mentalidad tradicional, toda muerte, sea por accidente 0 enfermedad es finalmente responsabilidad de un tercero, que la ha producido por mecanismos sobrenaturales. Con este convencimiento, estando ausentes los misioneros, los Pebas invitaron a una fiesta a los Ticunas y en ella mataron a los que no lograron huir $\left(^{(}\right)$.

Esta situación trajo también problemas con los Caumares, que temían que los Pebas los matasen. Esta parece ser una posibilidad que también temían los Jesuitas, por lo que a su llegada tuvieron que apaciguar a los Pebas (Zárate, pp. 441-2).

Veinte años después refiere Uriarte que en San Ignacio habitan nuévamente los Ticunas quienes conviven con los Yaguas, Cavachis, Pebas y Caumaris. En esta oportunidad la rivalidad se producia entre Ticunas y Caumaris y se manifestaba con mucha violencia en las fiestas de Carnavales (p. 237-8). A pesar de ello, los Ticunas siguen llegando a San Ignacio (p. 241),

(*) De acuerdo a Uriarte, conservaron vivas sólo a dos mujeres, pero poco después murió el Peba que había tomado por mujer a una de ellas. Uno de los hermanos del difunto, en la seguridad de que ella lo había hechizado, la mató.

106

DIGITALIZADO EN EL CENDOC - CAAAP 
pero, finalmente, en 1761 debió formarse la reducción de Nuestra Señora de Loreto a dos días de San Ignacio en la que fueron ubicados los Ticunas ( $p$. 286).

La convivencia no llegaba nunca a ser voluntaria o espontánea, por lo que se había desarrollado toda una estrategia al resepcto, procurándose incidir en la antigua amistad:

[aceptaron] hacer un barrio con sus amigos los cacumanos en Santa Bárbara; mas con la condición que no les hablasen de vivir en Napeanos con yameos (Uriarte, p. 205),

También eran importantes el parentesco (Maroni, p. 244) o la proximidad (Figueroa, p. 237) y podian aprovecharse las redes de intercambio comercial que los grupos indigenas mantenían.

En cuanto a poblaciones abiertamente enemigas, se planteaba un acercamiento paulatino. Por ejemplo, se permitía a los Yameos, que no deseaban reducirse, visitar San Joaquín de los Omaguas, hacer amistad con los nativos y aprender diversos oficios, de manera que a ambos grupos les fuera agradando la posibilidad de residir en el mismo pueblo (v. Brentano, en Maroni, p. 379).

Como los Jesuitas procuraban evitar las guerras entre los grupos indígenas, los nativos que evangelizaban tenían mejores relaciones y era más fácil plantearse la unidad.

De esta forma, Uriarte encargaba a los habitantes de la nueva reducción de San Miguel tener paz y amistad con otros curacas "con grandes esperanzas de que este pueblo había deser el emporio de la Misión, con toda la gente del Aguarico", con la que comerciaban.

Refiere también que tuvo éxito en unir a los Masamuas con los Cacumanos, "sus enemigos ancestrales (Ibíd., p. 356) y que en una reducción donde vivían los Necamumus, Blancos y Cacumanus aceptaron que llegasen loṣ habitantes del río Tigre, quienes no sólo habían sido sus enemigos, sino que huían de una epidemia (lbíd., pp. 398-9; v. Maroni, p. 292).

De acuerdo a los informes de los misioneros y visitadores en ninguna reducción habitaba un solo grupo étnico. Las relaciones entre los diferentes grupos parecen haber sido positivas (Uriarte, p. 165), aunque los Jesuitas

\section{DIGITALIZADO EN EL CENDOC - CAAAP}


debían cuidar que fuese así, viajando con nativos de distintas naciones o recogiendo las herramientas de todos para repararlas juntas y evitar disputas (lbíd., p. 210).

Los Jesuitas también debían evitar ser demasiado solícitos con los nativos que recién llegaban a la reducción, porque ocasionaba el resentimiento de los ya poblados y podía causar su fuga, así estuvieran varios años en la reducción (lbíd., p. 287).

No se producía, ni parece que se pretendiera, una verdadera unificación entre las "naciones". Se trataba más bien de una yuxtaposición, rota solamente por algunos matrimonios mixtos (Maroni, p. 373; Uriarte, p. 250), resaltados en los informes, por lo que sólo serían factibles en las reducciones más antiguas.

Generalmente, vivían en barrios diferentes (Magnin, loc. cit.) y cada grupo mantenía su idioma y sus autoridades. Tenemos que en una de las mejores reducciones, San Joaquín, convivieron muchas naciones durante el siglo XVIII (Uriarte, pp. 221 y 232-3). Sin embargo, predominaban los Omaguas, que tenían buenas relaciones con otros pueblos aún no reducidos, pero también tomaron como sirvientes a algunos de los que se reducían después.

Según Golob, se buscaba mantener la separación entre los grupos para que los Jesuitas pudieran ejercer mejor su poder sobre todos. Sin embargo, parece que más bien comprendían las dificultades de la integración y que no era práctico insistir en ella. En Juli existía una división similar.

A la vez que se reconocía la identidad de cada grupo, a todos se les instruía en el quechua como lengua franca, con lo que perdería asidero la tesis de que se buscaba impedir la comunicación entre los grupos.

\section{La Exclusión de los Españoles}

La Corona española había dispuesto que indios y españoles vivieran en pueblos separados, con la finalidad de evitar los abusos que podían realizar los segundos. Aunque los Jesuitas respetaron esta norma en las primeras reducciones, pronto manifestaron su necesidad de contar con el apoyo de viracochąs o colaboradores laicos, algunos de ellos casados y con hijos, 
quienes dirigian expediciones, enseñaban a los indios y velaban porque se cumplieran las órdenes de los misioneros.

Al mismo tiempo, solicitaban a la Audiencia de Quito el envío de tropas para proteger a las reducciones de las invasiones portuguesas y de las sublevaciones de los propios indígenas, así como para realizar las campañas contra los indios más indómitos (como los Jíbaros y los Cunibos). Finalmente, de manera esporádica estuvierón presentes en Maynas Gobernadores y Tenientes, quienes eran las autoridades políticas nombradas por la Corona.

Por otra parte, durante las primeras décadas de las reducciones los Jesuitas promovieron que los indios visitasen las ciudades de españoles. Se pensaba que los indios quedarían impresionados por la organización de las ciudades, la buena conducta de los españoles y el respeto que guardaban a los sacerdotes (Maroni, p. 206).

En ello influían como motivaciones prácticas la necesidad del despacho de Quito, la administración de la confirmación por el Obispo y la voluntad de presentar ante la Audiencia los éxitos alcanzados.

Sin embargo, los Jesuitas advirtieron que los nativos sólo aprendían malos hábitos y perdían la disciplina, por lo que optaron por restringir los viajes, inclusive aquellos del despacho, que se buscaba se limitasen solamente hasta la mitad del camino.

Yo conocí indio que fue bueno y por lo que vio se hizo borracho, diciendo: "También en Quito lo hacen" (Uriarte, p. 320).

Además se producian muchas muertes de indios, por lo que había que evitar que llegasen a tierras frías (5).

Situaciones parecidas se producían con las autoridades y tropas españolas. En algunos casos se produjeron conflictos por tratarse de personas con intenciones de enriquecerse a costa de los indios, con un poco disimulado servicio personal (Uriarte, p. 310). En otros se producía una innecesaria violencia al reprimir a los nativos o al realizar las expediciones (Id., p. 255).

Si bien las expediciones estaban a cargo de los Jesuitas, ellos no sólo podían obtener la remoción de los españoles que tenían mala conducta, a través de amonestaciones y quejas ante sus superiores, tanto más cuanto realmente los necesitaban para proteger a los propios indios. 
No tenemos referencia sobre cómo se disponía su presencia, pero probablemente tenían un campamento en las afueras. Cuando estaba presente, el Gobernador habitaba la vivienda que en las principales reducciones se construía en la Plaza Mayor.

\section{LA COACCION}

Desde los primeros momentos de la Conquista se percibió que no sería fácil entablar los "pueblos de indios" con medios pacíficos. Los misioneros que planteaban la "evangelización apostólica", lideradoś por de Las Casas sostenían que podrían congregar a los indios en poblados sin la presencia de soldados y entonces enseñarles la fe cristiana. Tuvieron la oportunidad de experimentar esta posibilidad en Venezuela y Honduras, pero fracasaron rotundamente, pues los indios abandonaban los poblados y se rehusaban a obedecer (Konetzke, pp. 244-7; v. también Hanke).

Surgió por tanto, también con fines religiosos, la seguridad de que era necesaria la coacción para acostumbrar a los indios a residir en poblados. Ello implicaba en algunos casos su captura violenta y el incendio de sus viviendas para que no pensasen en regresar.

En las misiones de Maynas se vivió de manera particular el proceso global. Luego que los indios abandonaron la primera reducción (Nuestra Señora de Xeberos), encontramos a los Jesuitas fomentando expediciones con tropas españolas e indígenas, en las que los indios eràn capturados y conducidos a las reducciones.

procurando cercar la primera casa que encuentran, y coger con el modo que se les ofrece algunas personas, y sosegándolas, si ay intérpretes, darles a entender la paz que procuran y que no ban a matarlos. Si no los ay sacan consigo a algunos muchachos, que después (...) sirven de intérpretes para reducir a sus parientes (Figueroa, p. 248).

Un cronista posterior nos revela la violencia que existía en estos casos:

el modo de reducirlos no es otro q. el cazarlos por los montes, como a fieras, yllevarlos a los pueblos, hasta ver el momento de formarles el suyo en sus sitios, dando muchas veces por bien empleada la correria, que se hace con cien indios y más, en el espacio de cuatro y seis semanas, si se encuentran una o dos piessas (Magnin, p. 473) v. lit.? 
Puede llamar la atención la existencia de mecanismos coactivos dentro de las reducciones, pues tratándose de una experiencia religiosa, debería ser libre. Debemos recalcar que para los Jesuitas los indios no eran sus adversarios ni buscaban tomarlos como prisioneros o como esclavos, sino los beneficiarios, puesto que finalmente recibian el Evangelio.

Los misioneros consideraban que los indígenas carecian de la facultad para utilizar su libertad como seres humanos y que debían ser educados para ello. En caso de que rechazasen esta educación, era justo y conveniente utilizar la fuerza, como se emplearia con un niño.

Debían por tanto verse sujetos a la tutela de los misioneros, y puesto que ello implicaba vivir congregados en pueblos se justificaba que en dicho proceso inclusive se violaran algunos derechos naturales de los indios, puesto que todo finalmente redundaba en su propio beneficio.

Señalaba de esta forma el pensador jesuita José de Acosta:

A todos estos que apenas son hombres o son hombres a medias, (...) si atrayéndoles con halagos se dejan voluntariamente enseñar, mejor seria; mas si se resisten (...) hay que contenerlos con fuerza y poder convenientes, y obligarles a que dejen la selva y se reunan en poblaciones $y$, aun en contra de su voluntad en cierto modo, hacerles fuerza (Lc. 14, 23) (Acosta, DPIS, p. 48).

De igual forma uno de los primeros misioneros de Maynas decía:

Es error y temeridad por falta de experiencia (si no es por milagro que Dios obre) el tratar e predicar y entablar cosa de importancia en estas gentes sin escolta y braço de españoles, porque la mesma brutalidad y costumbres estan fuera de razón destos indios, en que se crian, está clamando por justicia que los govierne, corrija y reprima (Figueroa, pp. 249-250).

Con mucha frecuencia se producian muertes o heridos por la resistencia de los nativos (Figueroa, p. 248; Maroni, p. 393-5), y los misioneros procuraban controlar a sus propias tropas. Sin embargo, parecía no existir otro medio posible.

Conforme las reducciones alcanzaban cierta estabilidad, los Jesuitas experimentaron con la posibilidad de conseguir la adhesión de los nativos mediante la entrega de herramientas a los nativos que encontraban y el 
ofrecimiento de entregarles más si aceptaban vivir en la reducción (p.e. Uriarte, p. 199).

De esta forma, se evitaban los excesos que se producían durante las expediciones violentas y los recuerdos traumáticos que originaba la captura. Las expediciones violentas se limitaban a contadas ocasiones en que, tratándose de indios "muy fieros", no era posible establecer un contacto pacífico.

Sin embargo, las herramientas colocaron a los nativos en una dramática dependencia tecnológica. La amenaza de no recibirlas o de que no fuesen reparadas era un factor de presión suficiente para forzar a los nativos a cumplir con las prescripciones jesuitas. De esta forma, la coacción, aunque suavizada, se mantenía.

Los Jesuitas admitían que debían a las herramientas la permanencia de los indios en las reducciones. Afirmaba Figueroa:"sin los dones de hachas y cuchillos no se haze nada" (p.323).

Se exhortaba a los misioneros a no entregar de una vez todas las herramientas, pues "si el indio huele que no tiene qué darle, no le hará caso o se irá al monte" (Uriarte, p. 119).

Salvo aquellas poblaciones con las que los misioneros pudieron trabajar intensivamente durante muchos años, la permanencia de los nativos en la reducción se basaba por tanto en la entrega de las herramientas y el temor a las incursiones portuguesas, así como a la violencia que los propios misioneros podían ejercer.

\section{CONSECUENCIAS PARA LOS NATIVOS}

Los nativos eran conscientes de que el patrón de asentamiento impuesto implicaba un serio peligro para su sobrevivencia. Al establecerse de forma definitiva en grandes poblados en los lugares escogidos por los misioneros eran no sólo más vulnerables a los ataques de grupos enemigos, sino sobre todo a las nuevas enfermedades y a las incursiones de bandeirantes portugueses (Golob, pp. 201-2). Con mucha frecuencia los peores de estos temores quedaron confirmados.

Refiere por ejemplo Maroni que, pese a tener un contacto amistoso, los Pinches, Pavas y Arazas declinaban reducirse a las orillas del Pastaza, 
prefiriendo formar dos poblaciones dentro del bosque. Luego de diez años de persuasiones los nativos accedieron a la invitación de los Jesuitas, pero quedaron diezmados por una terrible epidemia, debiéndose formar una nueva reducción lejos del río con los sobrevivientes (Maroni, p. 265; v. también el caso de los Icaguates, id. p. 266 y los Napeanos, Uriarte, p. 358).

Inclusive en casos de epidemias muchos Jesuitas no permitieron que los nativos dejasen la reducción o los recondujeron por la fuerza, así como persistieron en los traslados, a pesar que sabían el daño que causaban.

Como es común en mudanzas de pueblos, comenzaron a enfermar los buenos napeanos de cursos, y murieron más de cien (Maroni, p. 236).

Respecto a los bandeirantes, tenemos el caso de los numerosos pueblos que los Jesuitas tuvieron que trasladar hacia el Marañón debido a las incursiones que éstos realizaban, apoyados por religiosos carmelitas. Sin embargo, todos estos pueblos habían sido conducidos a las orillas del Amazonas por el Padre Samuel Fritz, quien, sin proponérselo había despertado la codicia de los portugueses ofreciéndoles a los indios ya concentrados en aldeas, siendo innecesario hacer incursiones en las selvas para capturarlos (Maroni).

Parecen haber persistido las tensiones al respecto, deseando los nativos:

(...) los paseos continuos que estilan mucho cuando gentiles, y quisieran continuar cuando xtianos, auséntandose y olvidando largo tiempo sus casas, hijos y doctrina (Maroni, p. 205).

En ocasiones los mecanismos coactivos que mantenían a los indios en la reducción fallaron o fueron insuficientes y podía producirse una fuga, una sublevación u optar el grupo por su autoeliminación.

Sin embargo, algunos nativos también aprendieron a manejar los mecanismos formales en los que se basaban los Jesuitas. De esta forma, tenemos el caso de un grupo de nativos que consiguen del Protector de Naturales de la Audiencia de Quito la suspensión del traslado. Esto demuestra que no existía un aislamiento absoluto de los indígenas respecto de la sociedad colonial, sino que la relativa integración que permitian los Jesuitas podia volverse inclusive en contra de los proyectos de los misioneros (Maroni, p. 231; ANH). 


\section{LOS CRITERIOS URBANOS DE LAS REDUCCIONES}

Los Jesuitas de Maynas recogieron al diseñar las reducciones las disposiciones reales y las dictadas en el Perú, mostrando unas concepciones urbanas preestablecidas y que solamente reflejaban el pensamiento europeo, sin mayores consideraciones con la mentalidad aborigen, ni sus necesidades.

El Renacimiento había representado en Europa un cambio en la concepción urbana pasándose del poblado adosado desordenadamente a los castillos, a la ciudad racionalimente diseñada con todos los servicios para el beneficio de sus habitantes. Se rescatan de la Antigüedad clásica conceptos arquitectónicos como la cuadrícula en el trazado de las calles y los grandes espacios abiertos (la piazza).

Fue en la América Española donde se dio la mayor oportunidad para el desarrollo de las nuevas corrientes urbanísticas, como apreciamos desde el impresionante proceso de fundación de ciudades hasta la estructura que se dispuso para las reducciones toledanas (Mörner, 1970, pp. 18-9).

Por ello, al referirnos al ordenamiento físico de las reducciones no pretendemos una finalidad descriptiva, sino recalcar su función simbólica de reflejar el orden a que estaban sujetos los nativos.

Se procuraba que el plano de la reducción representase la vida ordenada que los nativos debían llevar, centrada en torno a determinadas instituciones, disponiendo las casa "hermosamente a cordel" (Uriarte, p. 172), en torno a una gran plaza (lbíd., p. 110) a cuya cabecera estaba la iglesia, la casa del misionero (Maroni, p. 105) y el cabildo.

De acuerdo a Golob (p. 223), el cacique también tenía derecho de ubicar su casa en la plaza, pero esta afirmàción es dudosa, porque como hemos visto generalmente habían varios caciques y los nativos vivían en barrios separados.

En varios informes se hace referencia a un barrio de arriba y un barrio de abajo (Uriarte, pp. 175 y 193), lo cual es característico de la organización dual andina y lo recogieron los primeros juristas indianos (v. Matienzo).

Las calles eran anchas, lo cual dificultaba su mantenimiento en una región tropical: se requería que los indios trabajasen por turnos en la limpieza de la maleza que pronto crecía en calles y plazas. 
En las reducciones principales se contaba con almacén comunal, trapiche, taller de carpintería y fragua.

Los primeros misioneros parecen haber admitido la instalación de viviendas a la manera tradicional. En un informe al Virrey, el Padre De la Cueva sostiene la necesidad de dejarlos disponer el poblado

á su modo, como acostumbran mudarse en sus retiros y rancherias (...) Si esto se ejecuta con espacio y cuydado, no padecen tanto. Despues ban entablando y formando mejor sus pueblos, $y$ se hacen á vivir en ellos sin padecer tan graves inconvenientes (Figueroa, p. 251).

Apreciamos que, como Uriarte, el cronista plantea más bien una cuestión de plazos y de métodos, pero no cuestiona el objetivo general.

Las condiciones de inestabilidad de las reducciones de Mayras parecen haber llevado a los misioneros a no poder esperar que por sí solos los nativos entablen sus pueblos de manera adecuada; sino que debían disponer del trazado cuadrangular desde el principio.

Era establecida la distancia entre ellas, el plazo de construcción y el mantenimiento. Además debían tener determinadas proporciones y no "hacerse reparar de las demás por su extravagancia" (Chantre, p. 619).

Nosotros sostenemos que los jesuitas de Maynas alteraron el patrón de habitación en grupos familiares extensos para imponer viviendas unifamiliares, debido a su temor a la promiscuidad, como hicieron en el Paraguay.

Corroboran esta hipótesis la afirmación de que cuando un varón se casaba recibía una nueva casa, la afirmación de Chantre y Herrera sobre la rigurosa regulación a que estaba sujeta la construcción de casas por parte de los Jesuitas. Finalmente, todas las menciones con las que contamos a la vida familiar hacen referencia a familias nucleares.

Por otro lado, es posible que las viviendas hayan estado en ocasiones muy próximas, como formando un complejo. Decimos esto por la referencia al incendio de la reducción de Nombre de Jesús, imposible de extenderse de una casa a otra de ácuerdo al patrón de asentamiento tradicional. 
Los indios no tuvieron muchas posibilidades de modificar la estructura de la reducción. Si aquellas existieron, los cronistas prefirieron omitirlas, expresando que los nativos aceptaban el orden dispuesto por los misioneros.

Solamente hemos encontrado mención de dos iniciativas: en primer lugar, la edificación de una casa de orar, por unos nativos que recién se poblaban, lo que creemos que debe interpretarse más como un deseo de agradar al misionero que como fruto de una repentina conversión.

Con frecuencia eran los propios misioneros quienes obligaban a edificar la iglesia antes que el resto del pueblo y no sería extraño que se presente como una iniciativa lo que no era tal (Maroni, p. 110).

Por otro lado, cuando Uriarte describe la instalación de los nativos en Santa María, señala que además de sus casas edificaban

según su costumbre, una para parir, cerca, mas fuera del pueblo; porque dicen que es una indecencia para en la casa común, e impiedad dejarlas ir para esto al monte o río, como animales (reparen en esta sensación de unos gentiles) (Uriarte, p. 202).

Era inusual esta comprensión de las costumbres indígenas. En todo - caso, la concesión de Uriarte refleja su voluntád de respetar un rasgo cultural que para los nativos era importante dentro de su identidad como seres - humanos.

La estructura de los templos, majestuosa y acabada al lado de las viviendas de los nativos, procuraba representar el énfasis que debía tener la vida religiosa dentro de la reducción. En su interior se reflejaba la división jerárquica existente:

Veinticuatro bancos abajo para sentarse los indios y cuatro escaños para varayos y sacristanes, con su división y silla para el gobernador y teniente (Uriarte, p. 214).

se pusieron seis o siete filas de asientos para los niños;

más abajo, los de los mandones, y hasta la mitad de la iglesia seguían unos veinte bancos para los adultos: detrás seguian las niñas; luego las mujeres (...) y a los dos lados de la puerta dos asientos para los fisçales, que observașen (Ibid., p. 423). 
Al parecer, algunas autoridades coloniales consideraron fundamental esta ubicación, que para los misioneros no pasaba de ser un adecuado referente. Tenemos un caso extremo de estas discrepancias cuando un Gobernador español hizo poner en el cepo a unos capitanes indígenas que los misioneros toleraban se sentasen con los varayos (Ibid., p. 258).

\section{EPILOGO: LA COMUNIDAD NATIVA}

En 1989 se promulgó la Ley 24994 que promovía la colonización de la Selva, disponiendo que las poblaciones nativas se agrupasen en torno a las misiones religiosas. Dicha norma fue rechazada por la Iglesia Católica y por la población de la Amazonía, afirmándose en algunos sectores que se pretendía regresar a las reducciones coloniales (6)

Sin embargo, desde hace unos cuarenta años la Amazonía ha sido testigo del papel de las instituciones religiosas como base del asentamiento de los indígenas amazónicos.

En diversas zonas de la Amazonía se han establecido escuelas de diversas congregaciones católicas y del Instituto Lingüístico de Verano. En el primer caso, generalmente, se constituyeron internados en lugares céntricos a los que sólo debían trasladarse los estudiantes, pero se produjeron concentraciones de nativos en torno a la misión. En el segundo se generó un vasto proceso de formación de maestros bilingües, llevando a que en torno a las escuelas primarias se reunieran las familias con los niños pequeños. En muchos casos huían de esta forma de los patrones, caucheros o madereros.

Si bien mucho se ha criticado el papel de los grupos religiosos en la desaparición de las culturas tradicionales, lo cierto es que los nativos formados por las Parroquias y los maestros bilingües contaron con más elementos para resistir organizadamente las amenazas de la sociedad dominante a partir de los nuevos asentamientos.

En 1974, el Gobierno peruano legalizó esta situación otorgando mediante la Ley 20653 títulos de propiedad a los poblados indígenas, a los que se les proporcionó el nombre de "Comunidades Nativas". Se consideraba que por tratarse la Selva de una zona de frontera era peligroso otorgar reconocimiento jurídico y títulos de propiedad a las diferentes etnias en cuanto tales, dado que carecían de un sentido arraigado de patriotismo. 
La noción de Comunidad Nativa era en realidad un elemento tomado de las Comunidades Indígenas de la Sierra y de la Costa que reciben desde 1969 la denominación de Comunidades Campesinas.

A partir de ese año los funcionarios y técnicos del SINAMOS recorrieron la Amazonía con la finalidad de determinar cuáles eran las Comunidades Nativas. A pesar que era posible titular comunidades nómadas, los funcionarios tendían a considerar el grado de estabilidad de un núcleo poblacional, medido generalmente por la existencia de la escuela, que implicaba un asentamiento estable.

Las Comunidades Nativas han sufrido el recorte de sus derechos en varios casos. Por ejemplo, la Ley 22175 consideró que sobre las tierras forestales se podían tener solamente la cesión del uso, pero no la propiedad. Del mismo modo, muchas veces los encargados de titular las Comunidades reconocieron espacios insuficientes para la población, permitiendo al mismo tiempo la colonización de los terrenos adyacentes.

Sin embargo, actualmente, la Comunidad Nativa, una institución foránea, se ha convertido en el núcleo de identidad de la población indígena, produciéndose un fenómeno insospechable hace sólo un siglo, cuando los misioneros y los patrones buscaban, con finalidades diferentes, pero con dificultades parecidas, acostumbrar a los nativos a una vida sedentaria.

Creemos que en primer lugar, los nativos saben que son mucho más "vulnerables a los ataques de la sociedad dominante cuando no tienen instrucción. De allí que la escuela sea una necesidad, por la que pueden aćeptar sacrificar su vida nómada (además de otros servicios como la salud y bienes foráneos como kerosene y jabón, más factibles de recibir en un núcleo sedentario).

Por otra parte, la Comunidad Nativa es la primera forma de organización con respaldo legal a la que los nativos pueden acceder para defender sus derechos, y es la base para formas mayores de organización. La identidad cultural no ha desaparecido por la existencia de la escuela y de la comunidad. Las comunidades de un mismo grupo étnico se organizan en federaciones desde las cuales trabajan por el cumplimiento de sus derechos como grupo.

Para quienes sostienen que la residencia en poblados es opuesta a la cultura tradicional, habría que tener presente que es imposible hallar nativos en estado de pureza cultural. La penetración de la sociedad dominante ha 
dejado sus huellas desde hace más de 300 años; aprobemos o no sus consecuencias es un hecho de la realidad. Los nativos perciben actualmente la vida errante en los montes como un rasgo de atraso, de carácter antisocial y de mayor riesgo frente al resto de la sociedad.

Los criterios sobrenaturales, que otrora llevaban a los nativos a movilizarse continuamente, se han desvanecido y también han perdido su correlato práctico. Si en el siglo XVIII anté la muerte de un familiar por enfermedad, la huida era una forma de evitar el contagio, en la actualidad no permitiría recibir el tratamiento.

Por otra parte, el grupo étnico no asume el sedentarismo como un hombre occidental. En muchas ocasiones un nativo mígrará para establecerse con la familia de su esposa, para evitar un conflicto o para mejorar su posición económica, pero esta migración se producirá siempre hacia otro núcleo sedentario.

El principal obstáculo, finalmente, no parece estar dentro de la cultura, sino dentro de la ecología. Los habitantes de las Comunidades Nativas enfrentan la fragilidad del suelo amazónico explotando sucesivamente distintas parcelas dentro del mismo territorio de la Comunidad, manteniendo la misma vivienda. Muchas Comunidades han podido de esta forma llegar a una prosperidad que la forma de vida tradicional no permitiría por no ser posible la acumulación. Podríamos especular que esto pudo darse en algunas de las reducciones jesuitas más estables.

El problema mayor se presenta cuando la población nativa recibe un territorio muy poco productivo y no se le conceden las ampliaciones de tierras que señala la legislación.

Finalmente, la existencia de Comunidades Nativas no impide que al mismo tiempo se plantee la posibilidad de manejo de un espacio mayor por un grupo étnico. De esta forma la Legislación contempla la creación de Reservas Comunales con fines de subsistencia. La primera reserva comunal fue concedida en 1988 en la provincia de Oxapampa (Pasco), beneficiando a siete comunidades yanesha y varias federaciones han presentado propuestas semejantes.

Nuestra conclusión es que la residencia en poblados no es incompatible con la existencia de las poblaciones nativas. Existen como elementos 
básicos que la permiten la voluntad de la población para aceptarla con todas las modificaciones para la vida cotidiana que puede implicar, aunque alteren la cultura tradicional.

Evidentemente, los misioneros jesuitas del siglo XVII no tenían de los elementos para plantear un diálogo intercultural con las poblaciones amazónicas en el cual pudieran llegar a persuadir a los nativos de la conveniencia de la vida en las reducciones, más que coaccionar su presencia en ellas. Las graves consecuencias (bandeirantes, epidemias) que el sistema ocasionaba eran externas a las reducciones, pero los nativos las identificaban fácilmente. Finalmente, la regulación estricta de la vida cotidiana de acuerdo a criterios incomprensibles para los nativos generó que muchas veces se rompiera el delicado equilibrio que los mantenía en la reducción. 


\section{BIBLIOGRAFIA}

ACOSTA, JOSE DE. De Procuranda Indorum Salute, en OBRAS. Madrid, ed. Atlas, 1954. Historia Natural y Moral de las Indias. México, Fondo de Cultura Económica, 1979.

ACUÑA, CRISTOBAL DE. 1641. Nuevo Descubrimiento del Amazonas, IIAP-CETA, Iquitos, 1985 (Monumenta Amazónica t. B-1)

ANDA, ALFONSO. 1955. Los Primeros Gobernadores de Maynas. Los Generales Vaca de Vega, Quito

ARDITO, WILFREDO. 1991. "El Sistema Juridico de las Misiones Jesuitas de Maynas". Lima, Pontificia Universidad Católica del Perú. Tesis de Bachiller en Derecho.

ARMANI, ALbERTO. 1982. Ciudad de Dios y Ciudad del Sol. El Estado Jesuita de los Guaraníes. México, Fondo de Cultura Económica.

BALLON, FRANCISCO. 1978. Comunidad Nativa, Costumbre y Sistema Legal. Lima, Pontificia Universidad Católica del Perú. Tesis de Bachiller en Derecho.

1989. Sistema Jurídico Aguaruna y Positivismo. En América Indígena, vol. XLIX, t. 2.

BARNUEVO, RODRIGO DE. 1648. "Relación Apologética, así del Antiguo como del Nuevo Descubrimiento del Río de las Amazonas, hecho por los Religiosos de la Compañía de Jesús de Quito". IIAP-CETA (Monumenta Amazónica t. B-1).

BARON, EDMUND N. Design of Cities, Thomas and Hudson, London, 1969.

CHANTRE Y HERRERA, JOSE. Historia de las Misiones de la Compañía de Jesús en Marañón Español (1637-1767). Madrid, Aurial, 1901.

DE LA PEÑA MONTENEGRO, ALONSO. 1668. Itinerario para Párrocos de Indios. Guayaquil, Corporación de Estudios y Publicaciones.

\section{DIGITALIZADO EN EL CENDOC - CAAAP}


FIGUEROA, FRANCISCO DE. 1681. "Informe de las Misiones del Marañón, Gran Pará o Río de las Amazonas", IIAP-CETA (Monumenta Amazónica. B1).

GOLOB, ANN. 1982. "The Upper Amazon in Historical Perspective, Nueva York, Universidad de Nueva York", tesis para el Doctorado en Antropología.

GROHS, WALTRAUD. 1974. "Los Indios del Alto Amazonas, del siglo XVI al XVIII". Poblaciones y Misiones en la Antigua Provincia de Maynas. Bonn, Estudios Americanos de Bonn.

HANKE, LEWIS. 1959. La Lucha Española por la Justicia en América Latina. Madrid, Ed. Aguilar.

HEISE, MARIA; TUBINO, FIDEL; ARDITO, WILFREDO. 1992. Interculturalidad, un Desafío. Lima, Centro Amazónico de Antropología y Aplicación Práctica.

JOUANEN, JOSE. 1941-3 Historia de la Compañía de Jesús en la Antigua Provincia de Quito. Quito, Ecuatoriana, 2 t.

LASSEGUE, JUAN BAUTISTA. 1974. La Larga Marcha de Las Casas. Lima, CEP.

MAGNIN, JUAN. 1740. "Breve Descripción de la Provincia de Quito en la América Meridional". IIAP-CETA, Iquitos, 1988 (Monumenta Amazónica $B-4$ ).

MARONI, PABLO. 1738. "Nóticias Auténticas del Río Marañón". IIAPCETA. Iquitos, 1988 (Monumenta Amazónica t. B-4)

MARZAL, MANUEL. 1981. Las Reducciones Indígenas en la Amazonía Peruana durante el Virreynato, en América Indígena, n. 10, pp. 7-45).

MATIENZO, JUAN DE. 1567. Gobierno del Perú. Lima, Instituto Francés de Estudios Andinos, 1967.

MATTHEI, MAURO. 1969-70-71: Cartas e Informes de Misioneros Jesuitas en Hispanoamérica, 3t. En: Anales de la Facultad de Teología de la Universidad Católica de Chile; vol. XX-XXII. 
MEGGERS, BETTY. 1976. Amazonía: Hombre y Cultura en un Paraíso Ilusorio. Siglo XXI, Editores.

MURRAY, PETER. The Architecture of the Italian Renaissance. Thomasand Hudson, 1969.

PORRAS, MARIA ELENA. 1987. La Gobernación y el Obispado de Maynas (Siglos XVII-XVIII). ABIA-YALA y Taller de Estudios Históricos, Quito.

RODRIGUEZ, MANUEL. 1681. El Marañón y el Amazonas,

STAVENHAGEN, RODOLFO. 1989. Algunas Ideas sobre Derecho Consuetudinario en América Indígena, Vol. XLIX, t. 2.

STEWARD, JULIAN \& METRAUX, ALFRED. 1963. Handbook of South American Indians. Nueva York, Cooper Square Publisher, 5 t.

URIARTE, MANUEL. 1775. "Diario de un Misionero de Maynas". IIAPCETA, Iquitos (Monumenta Amazónica t. B-2).

URTEAGA, PATRICIA. 1990. La Conceptualización de los Derechos Humanos y la Identidad del Grupo Etnico Aguaruna.

VELASCO, JUAN DE. 1788. Historia del Reyno de Quito en la América Meridional. Quito, Orbis, 1979.

WOODMAN, GORDON. 1988. Indigenous Law and State. Dordrecht, Foris Publicationis Holland.

WOODMAN, GORDON \& MORSE, BRADFORD W. 1989. "The Peculiar Policy of Recognition of Indigenous Law in British Colonial Africa". En: Verfassung und Recht in Übersee, 22. Jährgang, 3. quartal, 1989, Baden-Baden, pp. 273-289.

ZARATE, AGUSTIN DE. 1739. "Relación de la Misión Apostólica de la Compañía de Jesús en el Gran Río Marañón". IIAP - CETA, Iquitos (Monumenta Amazónica t. B-4).

RECOPILACION DE LEYES DE INDIAS. 1680. Edición Facsimilar. Madrid, 1973. 


\section{NOTAS}

(1). Si en la Baja Edad Media la ciudad empieza a ser percibida como una entidad aparte, un todo en sí mismo, esta percepción se tralada a los diseños arquitectónicos. El Renacimiento asumió la tarea de tomar los modelos clásicos y los ideales de perfección y racionalidad en el diseño de nuevas ciudades. Surge entonces la preocupaión por disenar la ciudad ideal siendo una de las expresione más acabadas la Sforzinda de Filarete. Aparece entonces como una constante la estructura de la piazza en torno a la cual se concentra la vida de la ciudad y a la cual dan la Catedral y el Palacio Municipal. (Véanse Murray y Baron).

(2). Muchas veces inclusive tenían ciertas relaciones comerciales coexistentes con los conflictos (Figueroa).

(3). Muchas veces esta coacción pudo manifestar una severidad desproporcionada, por lo cual podemos afirmar que el reconocmiento de los derechos naturales de los indios se hallaba mediatizado por el interés superior de adecuar a los nativos a la vida de la reducción, en la que finalmente ellos, o sus descendientes, alcanzarían la plenitud como cristianos y como personas.

(4). Los Jesuitas consideraron las fugas de los nativos un grave delito y realizaron periódicamente expediciones en busca de fugitivos o "cimarrones", quenes eran conducidos violentamente a las reducciones, incendiándose sus nuevas casas.

Sobre la licitud de esta última acción opinó favorablemente el Obispo de Quito, lo cual demuestra la existencia de un debate ante el problema de que se destruían sus bienes. De la Peña afirmaba que las casas eran poco costosas y que el perjuicio era válido como penalidd por vivir dispersos (Peña, Lib. II, Trat. I, Sec. IX).

(5). Ante una epidemia un grupo de nativos insiste en huir al monte, donde no fuesen atacados, pero el misionero le dice que esos males también se dan en el monte y pueden ser castigo de Dios o para llevar al cielo a los buenos (Uriarte, p. 414).

(6). Debido a las presiones de distintas organizaciones e instituciones, la norma nunca llegó a ser aplicada y finalmente el Decreto Legislativo 6, Código de Medio Ambiente logró su derogatoria. 